\title{
Rancang Bangun Smart Meter System untuk Penggunaan Air pada Rumah Tangga Berbasis Internet Of Things
}

\author{
(Smart Meter System Design for Water Usage in Households Based on Internet of \\ Things)
}

\author{
Ramdani, I Gede Putu Wirarama Wedashwara W*, Ariyan Zubaidi \\ Program Studi Teknik Informatika, Universitas Mataram \\ Jl. Majapahit 62, Mataram, Lombok NTB, INDONESIA \\ Email: ramdaninformatika@gmail.com,wira@unram.ac.id, zubaidil3@unram.ac.id
}

\section{"Penulis korespondensi}

\begin{abstract}
Smart Meter System is now decreasing, mainly in urban areas and industrial centers. Water is one of the mineral resources which is a source of basic human needs and has many uses including drinking, bathing, washing and so on. In urban areas, clean water services are generally provided by the government through the PDAM (Regional Water Company). In the use of water, sometimes the user is not able to control the use of water which causes an enlarged water bill as in one of the houses in Pancor, East Lombok Regency. In this area, monitoring is still carried out conventionally by checking the water meter used. Monitoring systems are now widely used as an alternative way to monitor one of them in monitoring water use. In this study, a system (Smart Meter System) that dedicated to control, measure and record the data of water usage in the household for more efficient water use is designed. By using WeMos as a microcontroller, Water Flow Sensor and MQTT (Message Queuing Telemetry Transport) protocol as data communication, remote control and monitoring of water use in households can be done in real-time.
\end{abstract}

Key words: Internet of Things, WeMos, Water Flow Sensor, MQTT.

\section{PENDAHULUAN}

Indonesia memiliki sumber daya mineral yang sangat banyak tak terkecuali untuk kebutuhan seharihari[1]. Di perkotaan, pelayanan jasa air bersih umumnya diselenggarakan oleh pemerintah melalui PDAM (Perusahaan Daerah Air Minum). Setiap konsumen akan dipasangkan meteran air pada Rumah, Gedung, Kantor dan lain sebagainya yang terhubung dengan pipa distribusi. Meter air konfensional menggunakan baling-baling yang bergerak berdasarkan aliran air dan akan menambah kuantitas tagihan berdasarkan jumlah putaran balingbalingnya.
Dalam pemakaian air terkadang pengguna kurang dapat mengontrol penggunaan air dan juga kurangnya pengetahuan yang dimiliki beberapa pengguna untuk membaca meteran air saat ini dalam melakukan pemantauan, menyebabkan tagihan air yang dapat membesar pada akhir bulan seperti pada salah satu rumah di Pancor Kabupaten Lombok Timur. Di daerah tersebut masih melakukan melakukan proses pemantauan dengan cara konvensional yaitu melakukan pengecekkan pada meteran air yang digunakan. Proses pengecekkan ini juga sekaligus untuk mengetahui jumlah pemakaian pada bulan tersebut dengan menghitung selisih dari bulan sekarang dengan sebelumnya. Dari jumlah penggunaan tersebut digunakan untuk mengetahui uang yang harus dibayarkan dengan mengkalikan dengan nominal uang per satuannya (liter). Kurang efektifnya proses pengecekan dan pengontrolan air ini menyebabkan masyarakat kurang efisien dalam menggunakan air distribusi mengingat perkembangan teknologi yang ada saat ini dan dapat membantu permasalahan tersebut.

Sistem monitoring kini sudah banyak digunakan sebagai cara alternatif untuk melakukan pemantauan salah satunya dalam pemantauan penggunaan air. Namun sistem monitoring penggunaan air saat ini belum banyak menerapkan teknologi terbarukan seperti IoT (Internet Of Things)[2-4]. Penerapan IoT pada sistem monitoring ini akan menjadikan pemantauan air yang dilakukan secara manual berubah menjadi pemantauan secara digital. Dalam IoT terdapat banyak protokol yang dapat digunakan untuk melakukan pengiriman data seperti protokol MQTT (Message Queuing Telemetry Transport) [5.6], HTTP (Hyper Text Transfer Protocol)[7], CoAP (Constrained Application Protocol)[8] dan lain - lain. Pada sistem yang memerlukan data secara real time, protokol MQTT cocok digunakan karena memiliki delay pengiriman data dengan 
kualitas yang baik karena menghasilkan rata - rata delay sebesar 0.028183014 detik dan packet loss dari publisher ke server sebesar $0 \%$. Selain itu dengan adanya sistem kontrol pada sistem monitoring ini serta penggunaan protokol MQTT pada sektor pengirman datanya dapat memudahkan masyarakat dalam melakukan kendali dan pemantauan jarak jauh secara real time. Dengan menerapkan sistem ini data seperti debit dan volume air bisa didapatkan secara langsung dan dapat dilakukan kendali untuk jumlah air (volume) yang bisa dikonsumsi sampai waktu yang ditentukan.

Berdasarkan permasalahan yang telah dipaparkan, diperlukan penerapan IoT pada Smart Meter System untuk melakukan kontrol dan monitoring penggunaan air di Rumah Tangga untuk penggunaan air yang lebih efisien. Selain itu dengan penerapan konversi volume air ke nominal uang dapat menjadi solusi prabayar untuk air distribusi. Sehingga dengan penerapan IoT tersebut serta penggunaan protokol MQTT dapat dilakukan kendali dan pemantauan jarak jauh pada Smart Meter System secara real time.

\section{TINJAUAN PUSTAKA}

Penelitian terkait yang membahas smart meter menggunakan perangkat IoT telah dibahas pada penelitian [9]. Pada penelitian tersebut Fuzzy Association Rule Mining digunakan untuk mengukur dan memetakan kondisi pemanfaatan energi listrik. Pada penelitian ini smart meter mengukur aliran air tanpa menggunakan algoritma cerdas. Penelitian yang membahas pemanfaatan air untuk irigasi tanaman dengan menggunakan algoritma time series telah dibahas pada penelitian [10]. Pada penelitian tersebut aliran air diukur dengan kelembaban tanah sedangkan pada penelitian ini menggunakan sensor aliran air.

Penelitian terkait mengenai sistem monitoring kualitas udara yang pernah dilakukan. Pada penelitian 2015 menggunakan Water Flow Sensor sebagai sensor untuk mendapatkan data berupa debit air dan Raspberry pi sebagai mikrokontroller[11]. Penelitian [11] memiliki persamaan dengan penelitian Smart Meter System yaitu pada penggunakan Water Flow Sensor sebagai media untuk mendapatkan nilai debit air dan platform web sebagai interface dari sistem monitoring yang dibangun. Sedangkan untuk perbedaan sendiri pada penelitian [11] menggunakan Raspberry pi tipe $\mathrm{B}+$ sebagai microcontroller dan protokol HTTP sebagai media pengiriman data.

Kedua, pada tahun 2015 dilakukan penelitian oleh Masruchi dari Universitas Nasional tentang monitoring pemakaian air rumah PDAM berbasis SMS (Short Message Service)". Banyaknya pemakaian Air PDAM sebagai sumber distribusi Air Rumah Tangga mendasari Masruchi melakukan penelitian ini. Penelitian ini bertujuan untuk merancang Alat yang memudahkan konsumen untuk mengetahui berapa rupiah atau debit air yang di gunakan dengan menggunakan SMS. Dari penelitian ini didapatkan hasil berupa tingkat akurasi pada alat ukur (flowmeter) sebesar $98.9 \%$ [1]. Pada penilitian [1] dengan penelitian Smart Meter System memiliki persamaan pada sensor yang digunakan yaitu Water Flow Sensor. Untuk perbedaannya terletak pada microcontroller yang digunakan yaitu AVR dan media yang digunakan untuk menampilkan hasil atau output yaitu SMS.

Ketiga, pada tahun 2016 dilakukan penelitian untuk "Rancang Bangun Sistem Monitoring Aliran dan Harga Penggunaan Air PDAM menggunakan Arduino dan LabVIEW (Laboratory Virtual Instrumentation Engineering Workbench)" oleh Habibi Abdillah dari Institut Teknologi Bandung. Penelitian ini bertujuan untuk membangun sebuah alat yang dapat menghitung volume dan harga penggunaan air PDAM secara real time dengan menggunakan flowmeter elektronik, mikrokontroler Arduino, dan sistem antarmuka LabVIEW[12]. Pada penilitian [12] dengan penelitian Smart Meter System memiliki persamaan yaitu pada penggunaan Water Flow Sensor sebagai sensor pada Air. Sedangkan untuk perbedaannya yaitu pada penggunaan Arduino sebagai microcontroller dan LabView untuk antarmuka sistem monitoring.

Keempat, pada tahun 2016 dilakukan penelitian oleh Nine Shela Sadinda Agustine dari Universitas Jember tentang "Sistem Monitoring Air pada Reservoir PDAM Jember Menggunakan Sensor Ultrasonik dan Water Flow". Penelitian ini bertujuan untuk mengembangkan suatu alat berupa prototipe reservoir yang dapat digunakan untuk mengamati pengukuran debit, volume, dan tinggi air dan memberikan sinyal apabila air mendekati batas minimum atau maksimum dengan memanfaatkan Sensor Ultrasonik dan Water Flow. Data yang didapatkan dari penelitian Nine Shela Sadinda Agustine ini, dikirim melalui bluetooth serta ditampilkan dalam bentuk grafik dan disimpan dalam SD (Secure Digital) card[13]. Penilitian yang dilakukan oleh mahasiswa Universitas Jember ini [13] memiliki persamaan dengan penelitian Smart Meter System yaitu menggunakan Water Flow Sensor dalam mendapatkan debit air. Untuk perbedaannya antara lain terletak pada output yang dihasilkan yaitu tinggi, debit dan volume, penggunaan dua sensor termasuk Water Flow Sensor yaitu sensor ultrasonik, Arduino Uno sebagai microcontroller, bluetooth untuk media pengiriman data, dan LCD (Liquid Crystal Display) untuk menampilkan data. 
Kelima, pada tahun 2017 dilakukan penelitian tentang "Internet Of Things Untuk Penghitung Debit Air pada Depot Pengisian Air Minum Isi Ulang Berbasis Arduino" oleh Achmad Fathoni dari Universitas Narotama Surabaya. Dengan tujuan sebagai pemecahan masalah yang dialami distributor air isi ulang, dilakukan penelitian ini yang bertujuan untuk melakukan kontrol pada jumlah air minum yang distribusikan ke konsumen dengan memanfaatkan microcontroller Arduino serta memberikan informasi tersebut kepada pelanggan dan penjual. Dengan sistem yang dibangun ini, dapat dilakukan pemantauan pada jumlah air yang dikeluarkan pada setiap waktu dan dapat juga dilakukan report pada konsumen berupa jumlah air yang telah didapatkan oleh konsumen tersebut[14]. Dari penelitian [14] didapatkan persamaan dengan penelitian Smart Meter System yaitu sensor yang digunakan untuk mendapatkan nilai debit air yaitu Water Flow Sensor. Sedangkan perbedaannya terletak pada microcontroller yang digunakan yaitu Arduino R3 dan Ethernet Shield serta media yang digunakan untuk menampilkan hasil atau output yaitu LCD dan aplikasi berbasis Android.

Keenam, pada tahun 2017 dilakukan penelitian oleh Denny Kuriando dari Universitas Kristen Petra tentang "Pendeteksi Volume Air pada Galon Berbasis Internet of Things dengan Menggunakan Arduino dan Android". Pemanfaatan Arduino dan Android digunakan oleh Denny Kuriando untuk membangun prototype pendeteksi volume galon. Penelitian ini bertujuan untuk mendeteksi jumlah Volume Air Galon menggunakan aplikasi Android sehingga dapat melihat keadaan galon secara real time dan juga dapat memberikan notifikasi apabila volume air galon berada dibawah alert level. Selain itu pengguna juga dapat melihat laporan pemakaian galon per bulan [15]. Pada penilitian [15] dengan penelitian Smart Meter System memiliki persamaan pada sensor yang digunakan yaitu Water Flow Sensor dan microcontroller yang digunakan Wemos. Untuk perbedaannya terletak pada penggunaan aplikasi berbasis Android sebagai interface untuk menampilkan data.

Ketujuh, pada tahun 2018 dilakukan penelitian oleh Mochmad Subianto dari Universitas Ma Chung tentang "Rancang Bangun Prototipe Sistem Kontrol Penggunaan Air Prabayar Berbasis Arduino Uno". Penelitian ini bertujuan untuk pemecahan masalah pada penggunaan air yang tidak terkontrol pada Rumah Tangga yang dapat mengakibatkan pemborosan pada jumlah penggunaan air. Penelitian ini dilakukan pada rumah tangga pengguna jasa prabayar (Air PDAM) yang bertujuan untuk melakukan kontrol jumlah konsumsi air yang dapat digunakan dengan memanfaatkan Arduino Uno sebagai mikrokontroler. Dari penelitian yang telah dilakukan didapatkan akurasi perhitungan air yang masih kurang baik dengan rata-rata kesalahan $12.4 \%[16]$. Pada penilitian [16] dengan penelitian Smart Meter System memiliki persamaan pada sistem yang dibangun yaitu sistem kontrol penggunaan air, Water Flow Sensor sebagai sensor dan website sebagai media untuk menampilkan informasi. Sedangkan untuk perbedaannya terletak pada Arduino Uno sebagai mictrocontroller-nya.

Kedelapan, pada tahun 2018 dilakukan penelitian untuk "Implementasi Internet of Things Pada Sistem Monitoring Suhu dan Kontrol Air Pada Kandang Burung Puyuh Petelur dengan Menggunakan Protokol MQTT" oleh Zulhan Mindriawan dari Universitas Mataram. Penelitian ini bertujuan untuk membantu peternak ayam potong agar dapat memantau keadaan kandang seperti memantau jumlah makanan yang tersedia di tempat pakan ayam. Selain itu juga dapat melakukan pengendalian jarak jauh pada beberapa perangkat yang ada dengan bantuan microcontroller yang mengimplementasikan protokol MQTT[17]. Pada penelitian [17] dengan penelitian Smart Meter System memiliki persamaan pada protokol yang digunakan dalam melakukan pengiriman data yaitu MQTT. Sedangkan untuk perbedaannya terletak pada platform yang digunakan untuk melakukan monitoring yaitu Android.

Berdasarkan penelitian yang telah dilakukan tersebut, penerapan IoT pada Smart Meter System dapat dibangun untuk mendapatkan data berupa debit dan volume air, serta dapat dilakukannya kontrol pada jumlah konsumsi air yang digunakan dan batasan waktunya. Pada sektor pengiriman data dapat menggunakan protokol MQTT yang akan menyalurkan data ke pengguna.

\section{Metode Perancangan}

\section{A. Alur Penelitian}

Tahap pertama pada penelitian ini yaitu melakukan analisis kebutuhan sistem yang merupakan tahapan untuk mengidentifikasi kebutuhan dari sistem yang akan dibangun. Dari tahap pertama dilanjutkan ke perancangan arsitektur sistem yang didasari dari hasil tahap analisis kebutuhan sistem. Langkah selanjutnya adalah perancangan perangkat keras dilanjutkan dengan perancangan perangkat Lunak. Perancangan perangkat keras berkaitan dengan rancangan perangkat IoT berupa sensor dan microcontroller yang digunakan pada Smart Meter System. Sedangkan perancangan perangkat lunak berkaitan dengan perancangan protokol MQTT untuk pengiriman data dan web sebagai antar muka tempat menampilkan data. Setelah itu dilanjutkan ke tahap implementasi yang merupakan tahapan untuk membangun sistem kontrol dan monitoring berdasarkan tahapantahapan sebelumnya. Langkah selanjutnya adalah tahap pengujian sistem untuk melakukan pengujian terhadap sistem yang telah dibangun berupa sensor, kinerja protokol 
MQTT dan web. Jika hasil pengujian sistem tidak sesuai dengan kebutuhan sistem maka akan kembali ke tahap perancangan arsitektur sistem, namun jika hasil yang didapatkan sesuai maka dilanjutkan ke tahap dokumentasi laporan.. Adapun alur tahap penelitian ini dapat dilihat pada Gambar 1.

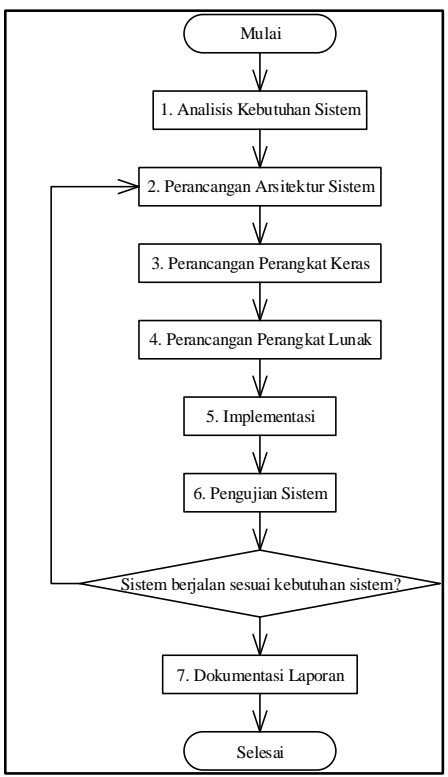

Gambar 1 Alur Tahap Penelitian

\section{B. Perancangan Perangkat Keras}

Pada tahap perancangan perangkat keras, akan dilakukan perancangan terhadap arsitektur sistem dan gambaran rangkaian dari Smart Meter System.

\section{B.1. Rancangan Arsitektur Sistem}

Gambaran dari arsitektur sistem yang akan dibangun dapat dilihat pada Gambar 2.

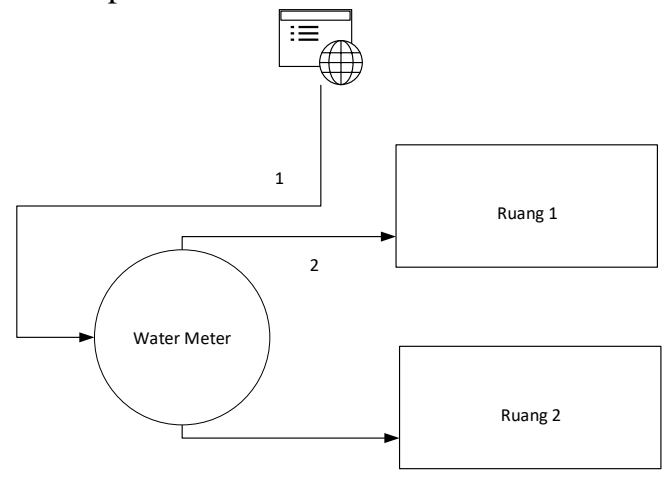

Gambar 2 Arsitektur Sistem

Pada gambar tersebut alur dari sistem berawal dari pipa distribusi yang meneruskan air ke setiap ruangan. Kemudian dari setiap ruangan akan di-monitoring jumlah penggunaan airnya. Terdapat dua proses dalam gambar di atas, antara lain sebagai berikut :

1. Web akan bertindak sebagai sistem informasi untuk menampilkan data-data berupa debit dan volume yang digunakan masing-masing ruangan. Dari web akan dihubungkan ke mikrokontroler yang ada pada pipa utama untuk melakukan kontrol dan monitoring.

2. Sensor, mikrokontroler dan alat IoT lainnya dipasangkan pada pipa utama. Pada proses ini akan berfungsi untuk mengontrol aliran air seperti membuka atau menutup aliran serta mengatur jumlah penggunaan air yang bisa dikonsumsi. Dari proses ini akan terhubung ke setiap ruangan untuk mendapatkan data jumlah penggunaan air dari masing-masing ruangan. Dari relasi ini juga dapat dimanfaatkan untuk membantu pengguna dalam mendeteksi kebocoran pipa pada setiap ruangan.

Adapun untuk Rancangan pada Pipa Utama adalah seperti Gambar :

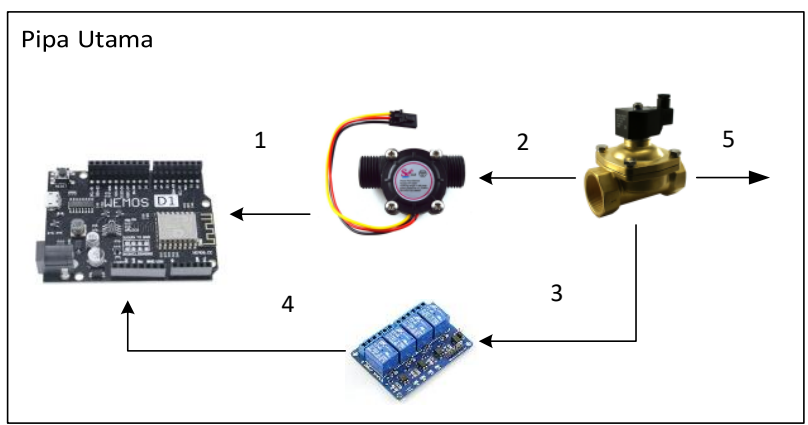

Gambar 3 Rancangan Perangkat Keras pada Pipa Utama

Berikut penjelasan dari masing-masing proses yang terdapat pada Gambar 3:

1. Water Flow Sensor dihubungkan ke WeMos untuk mendapatkan debit air yang mengalir pada pipa utama. Dari data ini akan didapatkan jumlah penggunaan air pada rumah tangga, serta dapat digunakan untuk melakukan pengecekan jumlah air yang dikonsumsi dengan batasan jumlah air yang sudah ditentukan.

2. Memasangkan Solenoid valve setelah Water Flow Sensor yang akan berfungsi untuk membuka dan menutup aliran air sesuai perintah yang dimasukkan.

3. Menghubungkan Solenoid valve dengan relay yang bertugas untuk memberikan daya yang dibutuhkan.

4. Dari relay dihubungkan dengan WeMos yang akan memberikan trigger ke relay untuk membuka dan menutup katup pada Solenoid valve.

5. Dari Solenoid valve setelahnya dihubungkan dengan pipa yang bertugas mengalirkan air ke setiap ruangan.

Sedangkan untuk Rancangan pada setiap ruangan terlihat pada Gambar 4. 


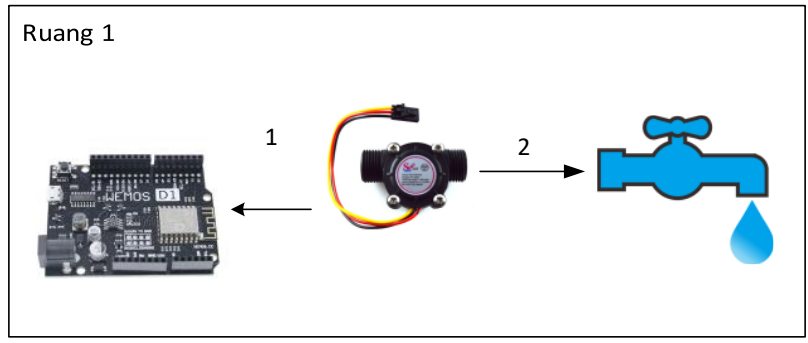

Gambar 4 Rancangan Perangkat Keras pada Setiap Ruangan

Berikut penjelasan dari masing-masing proses yang terdapat pada Gambar :

1. Water Flow Sensor yang ada pada setiap ruangan dihubungkan ke WeMos yang ada pada pipa utama untuk mendapatkan debit air dari masing-masing ruangan. Data ini akan digunakan untuk mendapatkan data jumlah penggunaan air secara spesifik pada masing-masing ruangan.

2. Dari Water Flow Sensor setelahnya dihubungkan dengan keran sebagai media untuk mengeluarkan air.

\section{B.2. Rangkaian Elektronika Sistem}

Gambaran dari rangkaian elektronika sistem yang akan dibangun dapat dilihat pada Gambar 5.

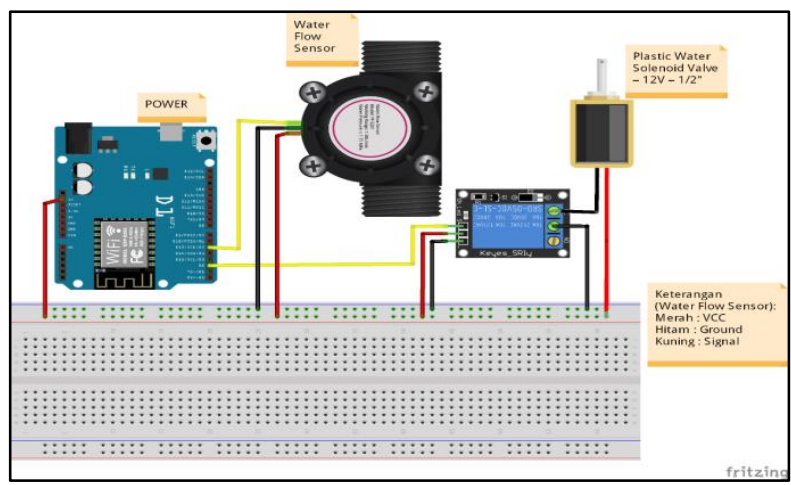

Gambar 5 Rangkaian Elektronika Sistem

Dari rangkaian pada Gambar 5 dapat dilihat bahwa terdapat dua input-an yang ada pada microcontroller yaitu Water Flow Sensor dan relay yang terhubung dengan Solenoid valve.

\section{Perancangan Perangkat Lunak}

Pada tahap perancangan perangkat lunak, dilakukan perancangan web Smart Meter System. Selain merancang $w e b$, pada tahap ini juga akan dilakukan pemrograman pada mikrokontroler dan perancangan alur komunikasi data antara perangkat keras dan perangkat lunak sistem.

\section{C.1. Use Case Diagram}

Use case pada sistem monitoring berbasis web yang akan dibangun yaitu User dapat melakukan aktivitas melihat data penggunaan air perkeran, membuka dan menutup aliran air, serta mengontrol jumlah volume air yang bisa dikonsumsi. Tiga aktivitas tersebut hanya dapat dilakukan setelah user melakukan aktivitas login. Adapun Rancangan use case web Smart Meter System yang akan dibangun dapat dilihat pada Gambar 6.

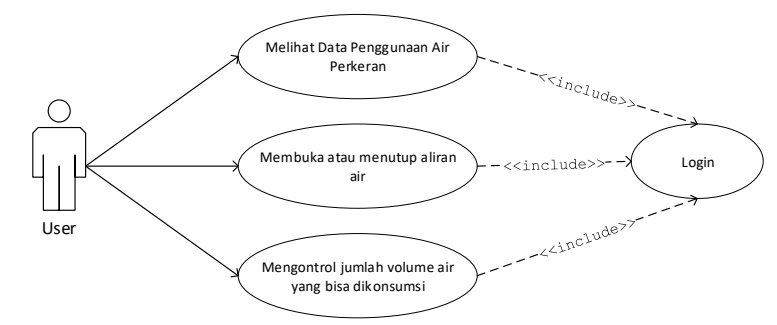

Gambar 6 Use Case Diagram

\section{C.2. Program Pada Mikrokontroler}

Selain merancang web, pada tahap ini juga akan dilakukan pemrograman pada mikrokontroler untuk mengambil data nilai dari sensor yang digunakan dan pengambilan keputusan untuk kontrol jumlah penggunaan air. Selain itu, mikrokontroler juga akan diprogram untuk bisa terhubung dengan jaringan internet dan mengirimkan data yang telah diperoleh ke mqtt broker. Proses pemrograman mikrokontroler ini akan dilakukan di aplikasi Arduino IDE dengan bahasa pemrograman $\mathrm{C}++$.

\section{C.3. Arsistektur Komunikasi Data}

Alur proses arsitektur komunikasi data MQTT ini dimulai dari Water Flow Sensor mengirimkan data (publish) yang didapatkan berupa debit air ke MQTT Broker melalui WeMos untuk ditampilkan pada web. Untuk media penyimpanan pada sistem informasi yang dibangun menggunakan NoSQL (Not Only Structured Query Language) yang akan menyimpan status, waktu, debit beserta volume dari setiap sensor yang ada. Gambaran alur komunikasi data MQTT dapat dilihat pada Gambar 7.

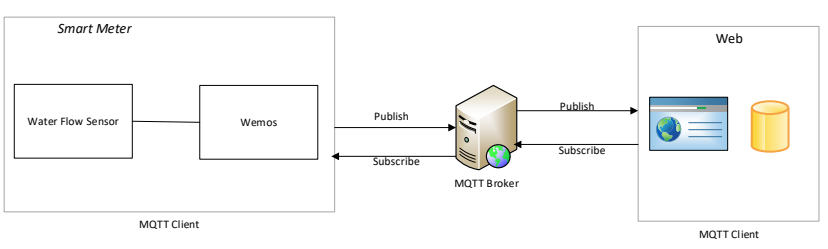

Gambar 7 Arsitektur Komunikasi Data MQTT

\section{Implementasi}

Pada tahap implementasi, akan dilakukan tiga proses yaitu:

1. Melakukan penyusunan perangkat keras berupa mikrokontroler WeMos D1 R2, Water Flow Sensor, modul relay dan Solenoid valve menjadi satu 
rangkaian perangkat keras sistem, yang disesuaikan dengan rancangan pada tahap rancangan perangkat keras sistem.

2. Melakukan pembangunan sistem monitoring berbasis web dengan menggunakan HTML, Python, MongoDB, framework Django dan bootstrap dan pemrograman pada mikrokontroler.

3. Melakukan pembangunan komunikasi data antara sistem web dengan perangkat keras yang telah disusun sebelumnya. Protokol komunikasi data yang digunakan yaitu menggunakan protokol MQTT dengan broker online "broker.hivemq.com".

\section{E. Pengujian dan Evaluasi Sistem}

Pada tahap pengujian dan evaluasi sistem, dilakukan pengujian pada sisi hardware dan software. Pengujian dari sisi hardware dilakukan untuk melakukan pengujian pada perangkat keras yang digunakan seperti Water Flow Sensor, microcontroller, relay dan Solenoid valve. Pengujian dari sisi software dilakukan untuk melakukan pengujian pada perangkat lunak yang digunakan dalam kasus ini yaitu sistem informasi berbasis website dan protokol MQTT sebagai sektor pengiriman data.

\section{HASIL DAN PEMBAHASAN}

Pada tahap ini akan membahas hasil dari penelitian yang dilakukan. Realisasi yang dilakukan telah dibuat sesuai dengan perancangan yang telah dijelaskan sebelumnya, selain membahas mengenai realisasi sistem, pada tahap ini juga akan membahas mengenai hasil pengujian sistem serta mengevaluasi sistem yang telah berjalan.

\section{A. Realisasi Perangkat Keras}

Realisasi penyusunan perangkat keras mengacu pada rancangan perangkat keras yang terdapat pada tahap sebelumnya. Pada realisasi penyusunan perangkat keras ini semua modul yang ada disatukan dalam satu prototype. Realisasi perangkat keras yang telah dibuat dapat dilihat pada Gambar 8.

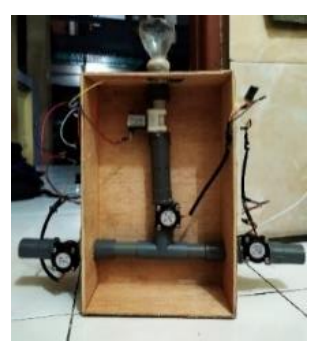

Gambar 8 Realisasi Perangkat Keras dari depan

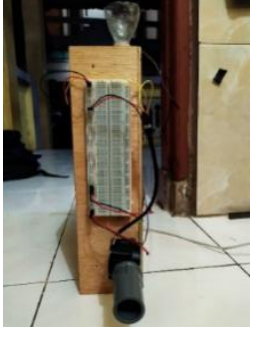

Gambar 9 Realisasi Perangkat Keras dari samping kanan

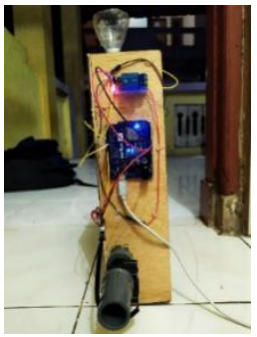

Gambar 10 Realisasi Perangkat Keras dari samping kiri

Terdapat lima perangkat keras yang dihubungkan menjadi sebuah alat di Gambar 8, Gambar 9 dan Gambar 10 yang terdiri dari breadboard, WeMos D1 R2, tiga Water Flow Sensor, modul relay dan Solenoid valve. Fungsi dari masing-masing perangkat keras tersebut adalah sebagai berikut :

1. WeMos D1 R2 digunakan sebagai mikrokontroler dari Smart Meter System.

2. Water Flow Sensor digunakan untuk mengetahui jumlah air yang mengalir (debit) yang akan diletakkan pada pipa utama dan pipa dari masing-masing ruangan.

3. Solenoid valve digunakan untuk mengontrol aliran air yang dalam kasus ini bertugas untuk membuka dan menutup aliran air dari pipa utama.

4. Relay digunakan untuk menyalakan dan mematikan Solenoid valve pada sistem.

5. Breadboard digunakan untuk meneruskan daya yang didapatkan dari mikrokontroler ke perangkat lain yang terhubung.

\section{B. Realisasi Pembangunan Database}

Dalam realisasi pembangunan database menggunakan MongoDB yang menggunakan struktur JSON dalam menyimpan data atau yang disebut dengan collections. Berikut adalah schema yang telah dibuat dalam pembangunan database yang diberik nama "web_sms" seperti pada Gambar 11. 


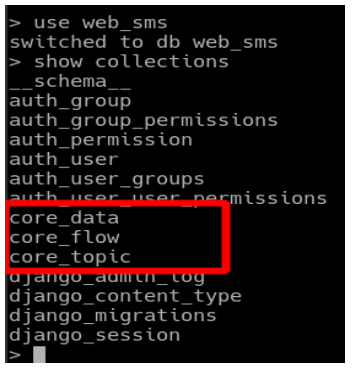

Gambar 11 Realisasi Database

\section{Realisasi Pembangunan Web Smart Meter System}

Realisasi interface yang dibangun yaitu halaman login, halaman dashboard, dan halaman data aliran air perbulan. Berikut merupakan hasil realisasi interface sistem yang telah dibangun sesuai dengan rancangan interface (seperti pada Gambar 12-14).

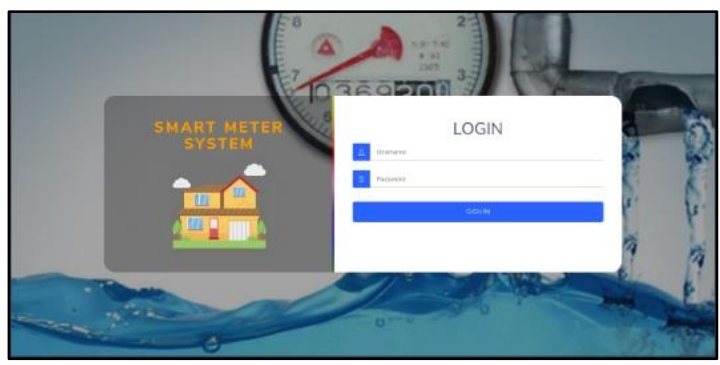

Gambar 12 interface Halaman Login

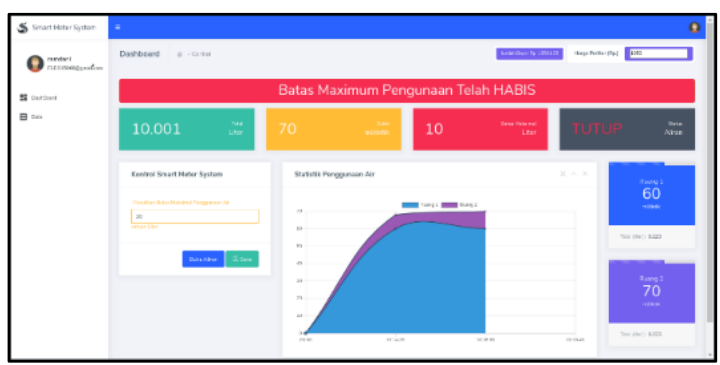

Gambar 13 Interface Halaman Dashboard

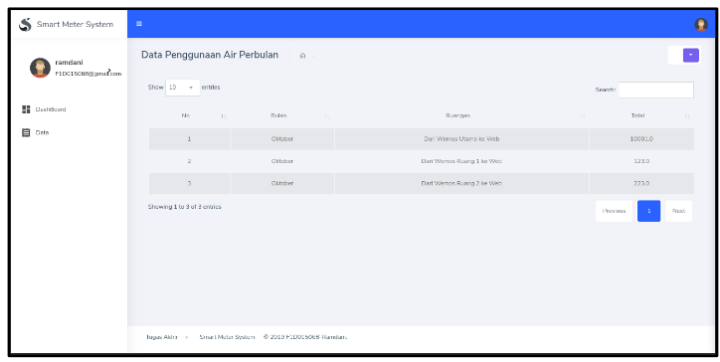

Gambar 14 Interface Halaman Data aliran air perbulan

\section{Realisasi Pembanguan Program Pada Mikrokontroler}

Realisasi pembangunan program pada mikrokontroler ini dilakukan dengan menggunakan bahasa pemrogaman C menggunakan aplikasi Arduino IDE. Berikut merupakan penjelasan source code program pada mikrokontroler.

\#include <ESP8266WiFi.h>
\#include <PubSubClient.h>
\#include <ArduinoJson.h>

Script di atas merupakan script untuk memasukkan library yang akan digunakan dalam program.

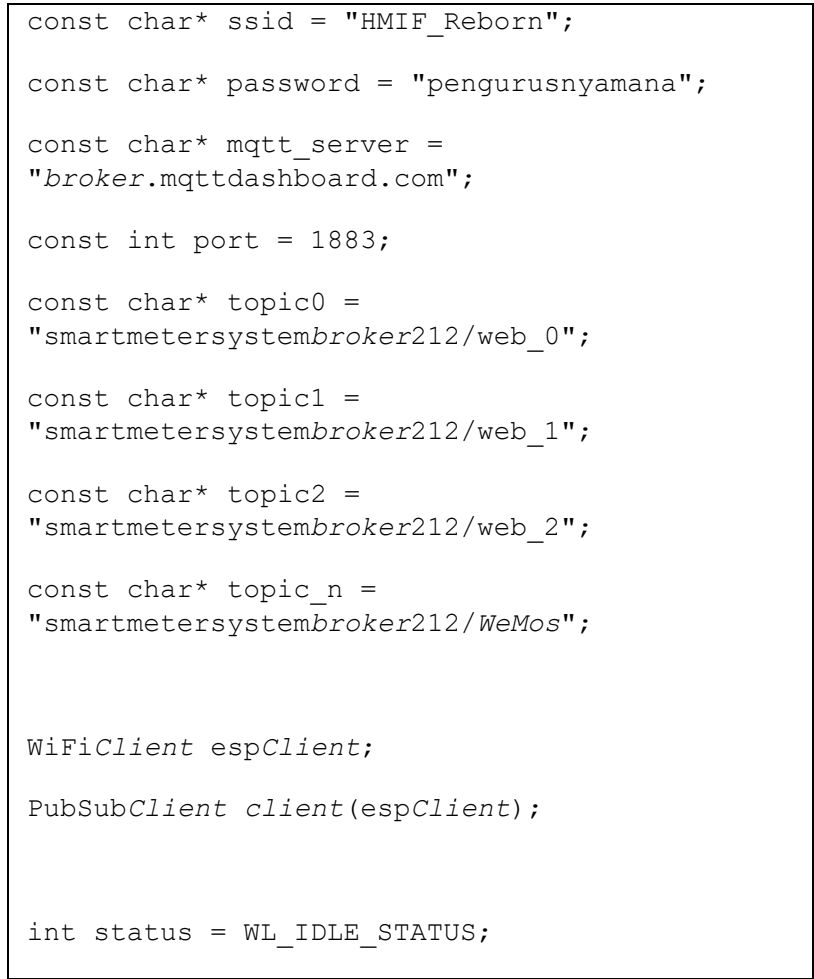

Script di atas merupakan script untuk mendeklarasikan variable-variabel wifi dan MQTT yang akan digunakan mikrokontroler WeMos D1 R2 dengan modul ESP8266 untuk terhubung dengan jaringan internet dan MQTT broker.

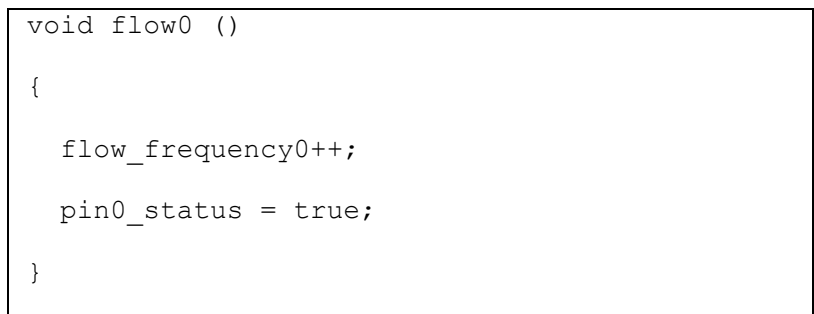

Script di atas merupakan script untuk melakukan increment untuk jumlah putaran yang didapatkan dari masing-masing sensor.

void callback(char* topic, byte* payload,
unsigned int length)
char* payload_out $=\left(\right.$ char $\left.{ }^{*}\right)$ payload;
payload_out [length] $=$ ' $\backslash 0$ ';
Serial.println(payload_out);




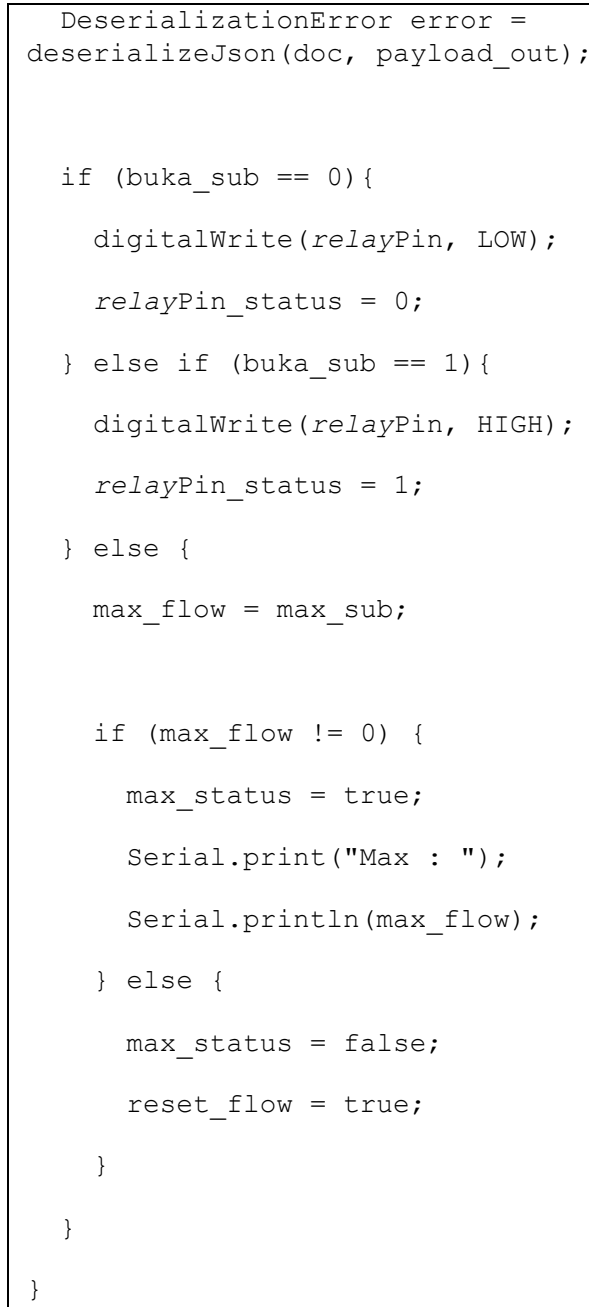

Script di atas merupakan fungsi yang bertugas untuk menangani pesan yang didapatkan dari broker pada topic yang sudah di-subscribe. Pada fungsi ini dilakukan kontrol untuk membuka dan menutup aliran air, jumlah maksimal penggunaan air dan reset data sensor.

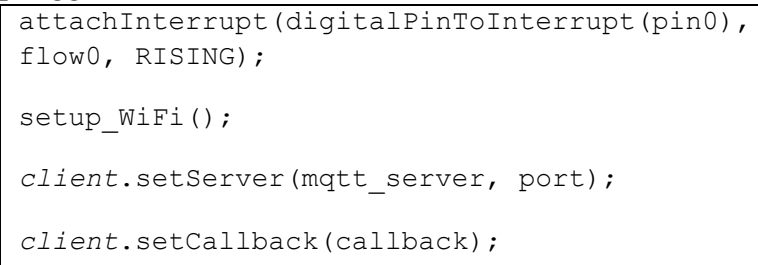

Script di atas merupakan fungsi untuk inisialisasi awal untuk semua pin, koneksi wifi dan protokol MQTT.

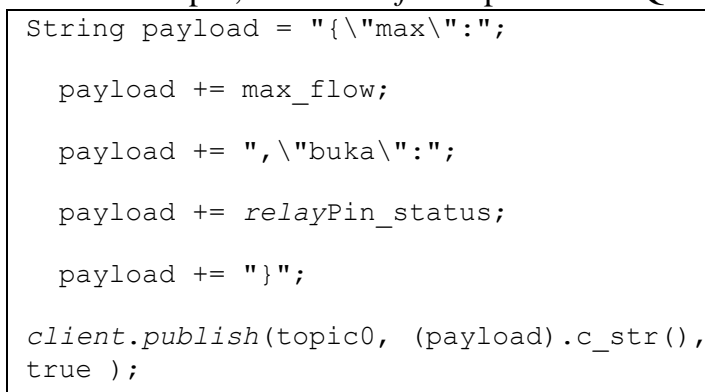

Script di atas merupakan berfungsi untuk melakukan publish ke broker dengan mengirimkan data berupa jumlah maksimal aliran dan status relay.

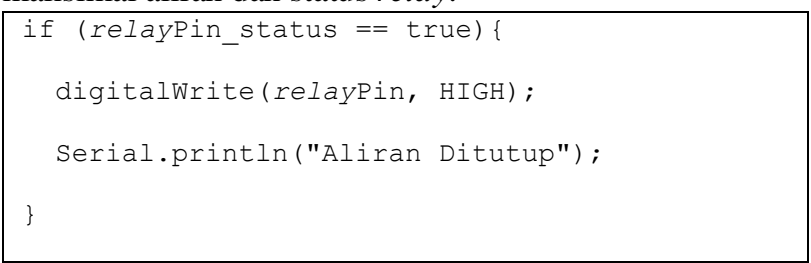

Script di atas berfungsi untuk menutup aliran air.

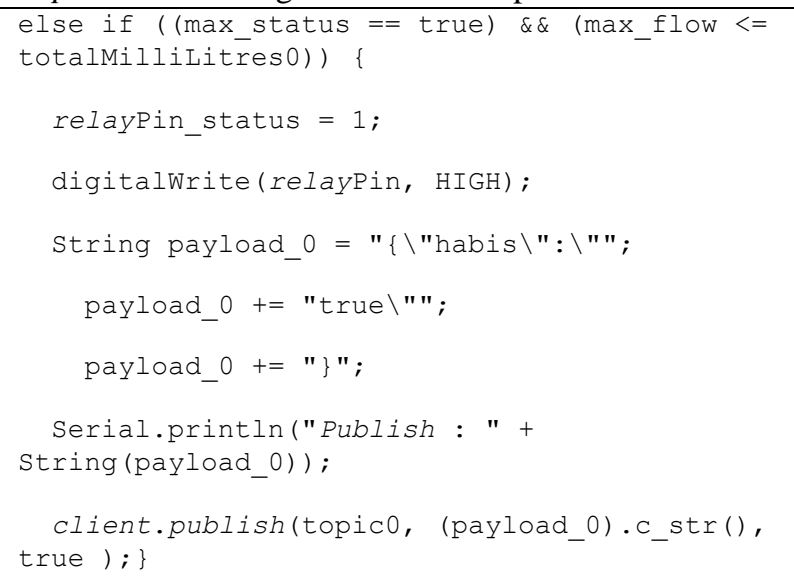

Script diatas berfungsi untuk menangani apabila jumlah dari nilai maksimal yang ditentukan sudah habis.

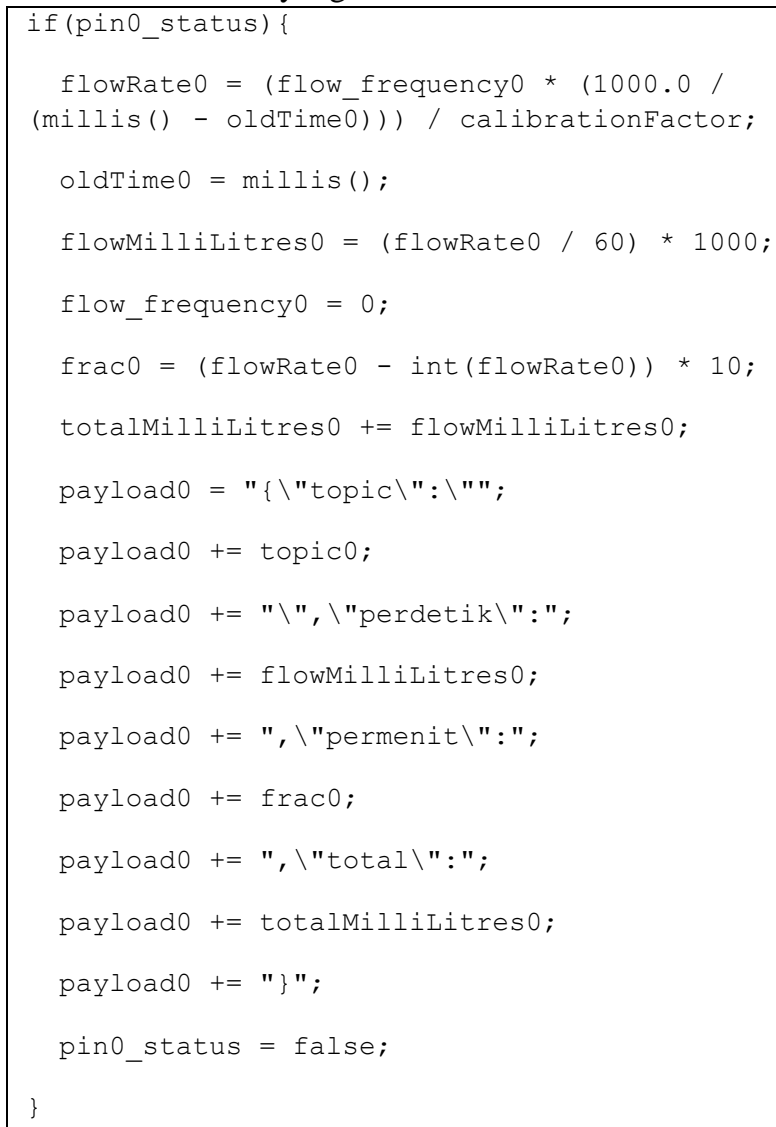

Script di atas bertugas untuk melakukan perhitungan untuk nilai debit dan volume dari masing-masing sensor. 


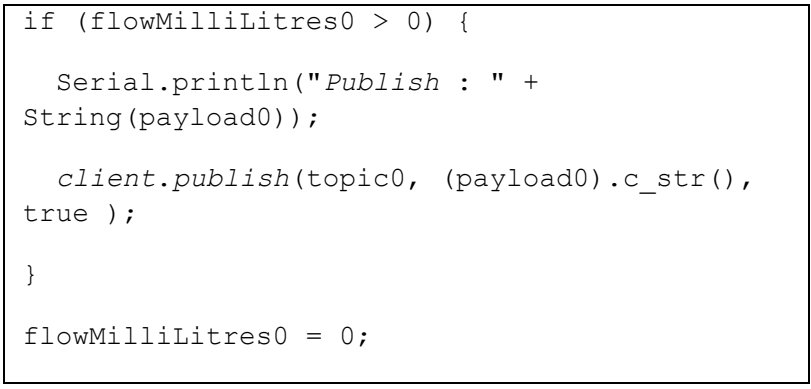

Script diatas bertugas untuk melakukan pengiriman ke broker dengan topik masing-masing berdasarkan pinnya.

\section{E. Realisasi Pembangunan Komunikasi Data MQTT}

Realisasi pembangunan komunikasi data MQTT ini dilakukan pada mikrokontroler untuk publish data sensor dan subscribe untuk menerima data untuk melakukan kontrol dari broker, pada backend digunakan program python untuk publish perintah reset ke broker dan subscribe untuk menyimpan data ke database, dan pada frontend digunakan javascript untuk publish data untuk kontrol dan subscribe untuk menerima data sensor dari broker.

\section{F. Pengujian dan Evaluasi Sistem}

Pengujian dilakukan untuk mengetahui apakah sistem yang dibangun berjalan dengan baik atau tidak. Skenario pengujian yang dilakukan adalah dengan mengalirkan air pada prototype Smart Meter System sebanyak 5 liter. Pada air 5 liter ini sensor-sensor akan melakukan pembacaan pada jumlah air yang dimasukkan tersebut, dan juga akan dilakukan kontrol dengan ditentukan jumlah batasan maksimal yang bisa digunakan melalui web Smart Meter System. Kemudian berdasarkan data pembacaan sensor dibandingkan dengan batas maksimal penggunaan air untuk mengambil keputusan dalam mengaktifkan atau mematikan relay yang terhubung dengan Solenoid valve. Kemudian dilakukan pengujian membuka atau menutup aliran Solenoid valve dengan cara mematikan atau mengaktifkan relay melalui web Smart Meter System.

\section{F.1. Pengujian Water Flow Sensor}

Pengujian yang dilakukan adalah mengukur persentase error dari kalibrasi yang digunakan. Pengujian dilakukan dengan cara mengalirkan air sebanyak $600 \mathrm{ml}$ dari pipa utama pada masing-masing nilai kalibrasi. Berdasarkan pengujian yang dilakukan didapatkan nilai kalibrasi yang digunakan yaitu 6.0 dengan persentase error $4,5 \%$ seperti pada Tabel I.

\section{F.2. Pengujian Solenoid valve}

Pengujian yang dilakukan adalah mengecek apakah solenoid valve yang digunakan dapat terbuka jika dialirkan listrik. Berdasarkan pengujian yang dilakukan didapatkan hasil bahwa solenoid valve sudah dapat berjalan dengan baik seperti pada Tabel II.
TABEL I. Pengujian Water Flow SensoR

\begin{tabular}{|c|c|c|}
\hline \multirow{2}{*}{ No } & \multicolumn{2}{|c|}{ Water Flow Sensor } \\
\cline { 2 - 3 } & Kalibrasi & Persentase error (\%) \\
\hline 1 & 4,5 & 33,67 \\
\hline 2 & 5,5 & 16,5 \\
\hline 3 & 6,5 & 10,67 \\
\hline 4 & 6,0 & 4,5 \\
\hline
\end{tabular}

TABEL II. PenguJian SOlENOID VALVE

\begin{tabular}{|c|c|}
\hline Aliran Listrik & Kondisi \\
\hline Low & Tertutup \\
\hline High & Terbuka \\
\hline
\end{tabular}

\section{F.3. Pengujian Modul Relay}

Pengujian yang dilakukan adalah mengecek apakah modul relay berfungsi dengan baik dalam membuka dan menutup aliran pada Solenoid valve. Berdasarkan pengujian yang dilakukan didapatkan hasil bahwa modul relay sudah dapat berjalan dengan baik seperti pada Tabel III.

TABEL III. PenguJian MOdL RELAY

\begin{tabular}{|c|c|c|}
\hline Aliran Listrik & Relay & Solenoid valve \\
\hline Low & Off & Tertutup \\
\hline High & On & Terbuka \\
\hline
\end{tabular}

\section{F.4.Pengujian Web Smart Meter System}

Pengujian fungsi fitur web ini dilakukan untuk mengetahui apakah fungsi ini sudah berjalan dengan baik dan benar. Adapun fungsi yang diuji adalah fungsi login, fungsi logout, monitoring aliran air, kontrol jumlah penggunaan air, membuka dan menutup aliran air serta filter data setiap ruangan perbulan. Berdasarkan pengujian yang telah dilakukan dapat disimpulkan bahwa enam fungsi fungsi tersebut sudah berjalan dengan baik dan benar.

\section{G. Hasil Pengujian Keseleruhan Sistem}

Pada pengujian fungsi keseluruhan sistem ini dilakukan sebuah skenario pengujian untuk mengetahui apakah sistem yang dibangun berjalan dengan baik atau tidak. Pengujian dilakukan sebanyak lima kali dengan mengalirkan air pada prototype Smart Meter System sebanyak masing-masing 5 liter. Pada air 5 liter pertama akan dilakukan kontrol dengan ditentukan jumlah batasan yang bisa digunakan sebesar 2 liter melalui web Smart Meter System. Kemudian dilakukan pengujian membuka atau menutup aliran Solenoid Valve dengan cara 
mematikan atau mengaktifkan relay melalui web Smart Meter System. Sedangkan untuk pengujian kedua sampai dengan kelima dilakukan kontrol air sampai batas maksimal 5 liter. Adapun hasilnya adalah seperti Gambar 15.

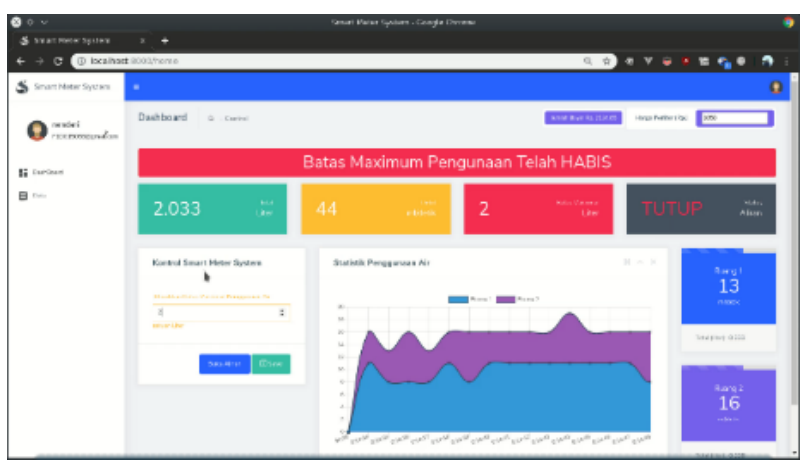

Gambar 15 Hasil kontrol maksimal penggunaan air

Dari Gambar 15 diketahui setelah jumlah pemakaian melebihi batas maksimal maka modul relay akan aktif dan Solenoid valve pada prototype Smart Meter System akan tertutup untuk menutup aliran air, dan pada web akan memberikan status bahwa jumlah pemakaian sudah melewati batas yang ditentukan. Sehingga hasil pengambilan keputusan yang dilakukan untuk kontrol jumlah penggunaan air adalah benar. Setelah aliran air tertutup, batas maksimal penggunaan air diperbarui untuk membuka aliran air dengan mengirimkan perintah melalui web Smart Meter System seperti pada Gambar 16.

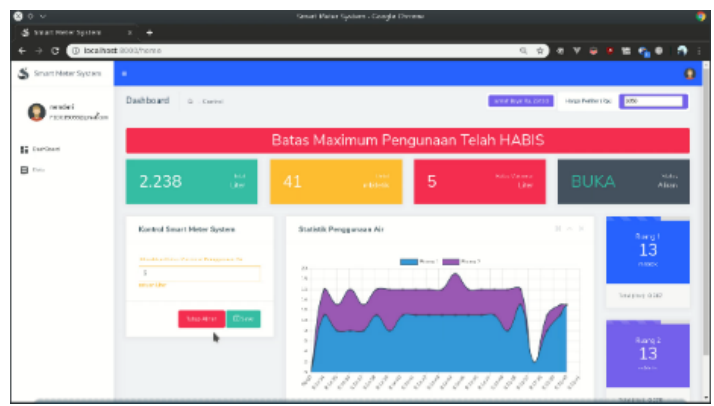

Gambar 16 Update maksimal penggunaan air

Dari Gambar 16 dapat dilihat bahwa ketika nilai batas maksimal diperbarui aliran sebelumnya yang berada pada kondisi tertutup terbuka untuk mengalirkan air kembali. Selanjutnya dilakukan pengujian untuk menutup dan membuka aliran air. Adapun hasilnya seperti pada Gambar berikut :

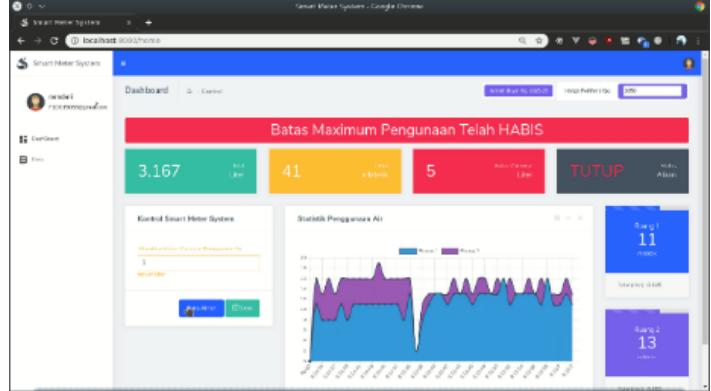

Gambar 17 Kontrol menutup aliran air

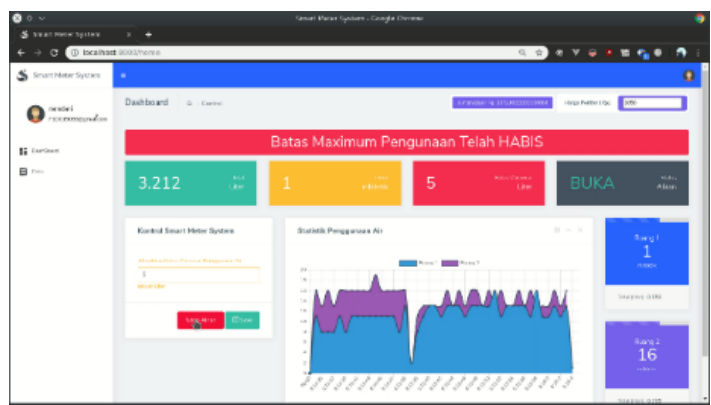

Gambar 18 Kontrol membuka aliran air

Dari Gambar 17 dan Gambar 18 Diketahui bahwa hasil dari keputusan dari perintah untuk menutup dan membuka aliran air maka Solenoid valve adalah benar. Untuk hasil akhir dari pengujian dapat dilihat pada Gambar 19.

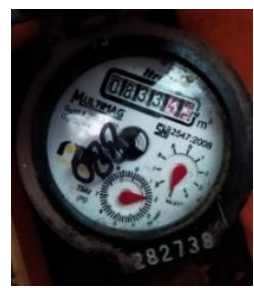

Gambar 19 Nilai incometer setelah pengujian

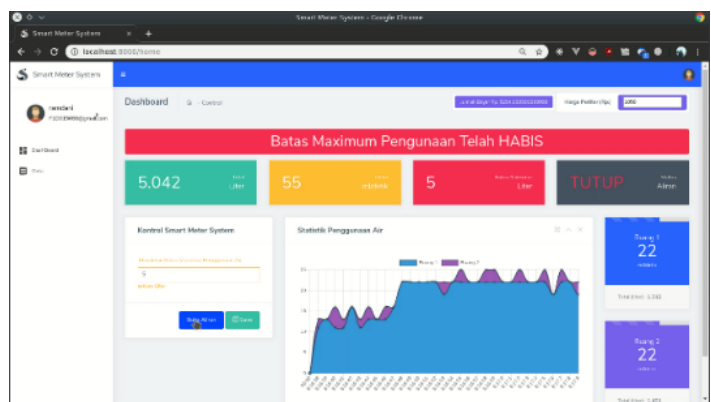

Gambar 20 Hasil akhir pengujian Smart Meter System

Dari Gambar 20 diketahui jumlah air yang didapatkan pada Water Flow Sensor utama sebesar 5,042 liter, Water Flow Sensor 1 sebesar 1,312 liter dan Water Flow Sensor 2 sebesar 1,401 liter. Untuk data perbulan dapat dilihat pada halaman Data seperti Gambar 21. 


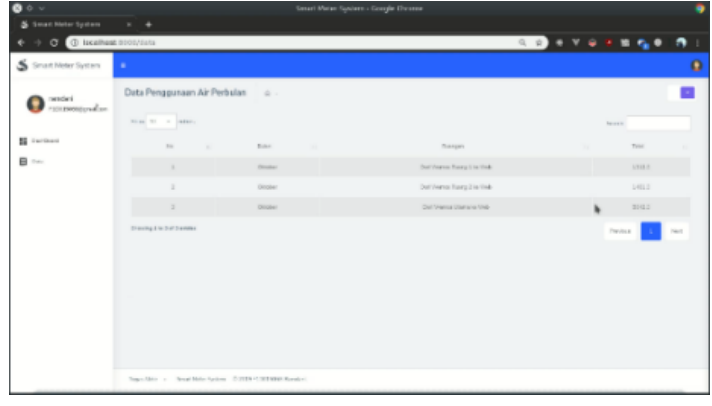

Gambar 21 Data penggunaan air perbulan

Adapun untuk data pada database-nya dapat dilihat pada Gambar 22.

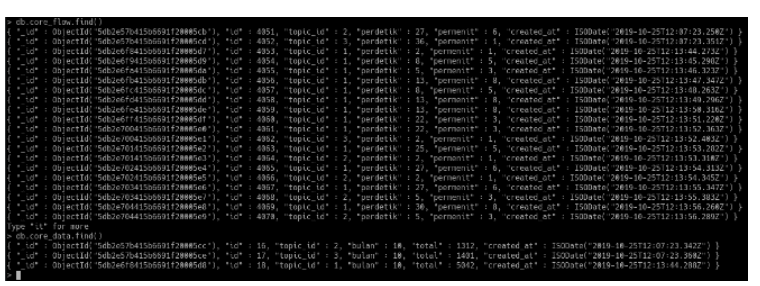

Gambar 22 Data pada database "web sms"

Dari Gambar 22 dapat dilihat bahwa data yang ada sama dengan yang ditampilkan pada web sehingga hasil pembacaan data pada masing-masing sensor memberikan hasil yang benar. Adapun untuk hasil akhir seluruh pengujian adalah seperti pada Tabel IV.

TABEL IV. HASIL AKHIR SELURUh PenguJAan

\begin{tabular}{|c|c|c|c|c|c|}
\hline \multirow{2}{*}{ Pengujian } & \multirow{2}{*}{ incometer } & \multicolumn{3}{|c|}{ Sensor } & \multirow{2}{*}{$\begin{array}{c}\text { Persentase } \\
\text { error (\%) }\end{array}$} \\
\cline { 3 - 5 } & & Utama & 1 & $\mathbf{2}$ & \\
\hline 1 & 5,31 & 5,042 & 1,312 & 1,401 & 5,04 \\
\hline 2 & 4,44 & 5,069 & 1,995 & 2,121 & 14,17 \\
\hline 3 & 4,72 & 5,064 & 2,206 & 2,248 & 7,28 \\
\hline 4 & 4,62 & 5,029 & 2,101 & 2,230 & 8,85 \\
\hline 5 & 4,64 & 5,021 & 2,114 & 2,229 & 8,21 \\
\hline
\end{tabular}

Dari hasil Tabel IV didapatkan rata-rata persentase error sebesar $8.71 \%$ dengan kalibrasi 6 ml/detik.

\section{KESIMPULAN DAN SARAN}

\section{A. Kesimpulan}

Berdasarkan penelitian yang telah dilakukan, maka kesimpulan yang dapat diambil dari penelitian ini adalah sebagai berikut :

1. Rangkaian elektronika Smart Meter System yang dibuat sudah bisa melakukan monitoring untuk mendapatkan data berupa debit air dan volume air dari masing-masing Water Flow Sensor.

2. Prototype yang dibangun telah dapat melakukan kontrol pada jumlah penggunaan air berdasarkan batasan volume yang ditentukan untuk menutup aliran air.

3. Sistem web yang dibangun telah dapat melakukan monitoring dengan menampilkan data debit air dan volume dari masing-masing sensor serta ditampilkan dalam bentuk grafik.

4. Data yang didapatkan pada sistem telah dapat disimpan ke database MongoDB pada tiga collections yang dibuat yaitu Topic, Data dan Flow.

5. Komunikasi data menggunakan protokol MQTT telah berjalan dengan baik, dengan menggunakan "broker.hivemq.com" sebagai broker online yang bersifat open source.

6. Sistem yang dibangun telah dapat melakukan monitoring dan kontrol pada penggunaan air rumah tangga dengan menggunakan WeMos D1 R2 sebagai mikrokontroler dengan rata-rata persentase error yang didapatkan sebesar 8,71 \% pada lima kali pengujian

\section{B. Saran}

1. Sistem ini diharapkan dapat dikembangkan untuk mengontrol pengisian tempat penampungan air.

2. Sistem ini diharapkan dapat dikembangkan untuk menambah sensor ultrasonik untuk mengetahui penuh atau tidaknya tempat penampungan air.

\section{DAFTAR PUSTAKA}

[1] V. V. R. Repi and F. Hidayanti, 2015, "Perancangan Sistem Pengukuran dan Monitoring Pemakaian Air Rumah PDAM Berbasis SMS ( Short Message Service )", Program Studi Teknik Fisika, Fakultas Teknik dan Sains, Universitas Nasional.

[2] Choo, K. K. R., Gai, K., Chiaraviglio, L., \& Yang, Q. (2020). A Multidisciplinary Approach to Internet of Things (IoT) Cybersecurity and Risk Management.

[3] Albahri, A. S., Alwan, J. K., Taha, Z. K., Ismail, S. F., Hamid, R. A., Zaidan, A. A., ... \& Alsalem, M. A. (2020). IoT-based telemedicine for disease prevention and health promotion: State-of-the-Art. Journal of Network and Computer Applications, 173, 102873.

[4] Rahman, A., Islam, M. J., Rahman, Z., Reza, M. M., Anwar, A., Mahmud, M. P., ... \& Noor, R. M. (2020). DistB-Condo: Distributed Blockchain-Based IoTSDN Model for Smart Condominium. IEEE Access, 8, 209594-209609.

[5] Hindy, H., Bayne, E., Bures, M., Atkinson, R., Tachtatzis, C., \& Bellekens, X. (2020). Machine Learning Based IoT Intrusion Detection System: An MQTT Case Study. arXiv preprint arXiv:2006.15340.

[6] Sochor, H., Ferrarotti, F., \& Ramler, R. (2020, September). An Architecture for Automated Security 
Test Case Generation for MQTT Systems. In International Conference on Database and Expert Systems Applications (pp. 48-62). Springer, Cham.

[7] An, Y., Yu, F. R., Li, J., Chen, J., \& Leung, V. C. (2020). Edge Intelligence (EI)-Enabled HTTP Anomaly Detection Framework for the Internet of Things (IoT). IEEE Internet of Things Journal.

[8] Majumder, S., Ray, S., Sadhukhan, D., Khan, M. K., \& Dasgupta, M. (2020). ECC-CoAP: Elliptic Curve Cryptography Based Constraint Application Protocol for Internet of Things. Wireless Personal Communications, 1-30.

[9] Wedashwara, W., Ahmadi, C., Arimbawa, I. W. A., \& Putra, I. G. E. W. (2019, September). Internet of Things based Smart Energy Audit using Evolutionary Fuzzy Association Rule Mining. In 2019 International Conference on Sustainable Information Engineering and Technology (SIET) (pp. 142-147). IEEE.

[10] Wedashwara, W., Ahmadi, C., \& Arimbawa, I. W. A. (2019, December). Sequential fuzzy association rule mining algorithm for plants environment classification using internet of things. In AIP Conference Proceedings (Vol. 2199, No. 1, p. 030004). AIP Publishing LLC.

[11] A. B. Wijaksono, 2015, "Desain Sistem Monitoring Debit Air Menggunakan Protokol HTTP”, Jurusan Teknik Elektro Fakultas Teknik Universitas Jember.

[12] H. Abdillah, S. Hartati, and A. Suaif, 2016, "Rancang Bangun Sistem Monitoring Aliran dan Harga
Penggunaan Air PDAM menggunakan Arduino dan LabVIEW", Kelompok Keilmuan Fisika Teoretik Energi Tinggi dan Instrumentasi Fakultas Matematika dan Ilmu Pengetahuan Alam, Institut Teknologi Bandung.

[13] M. I. Fitrianda, 2016, "Sistem Monitoring Air Pada Reservoir PDAM JEMBER Menggunakan Sensor Ultrasonik dan Water Flow", Jurusan Teknik Elektro Fakultas Teknik Universitas Jember.

[14] A. Fathoni and S. Winardi, 2017, "Internet Of Things Untuk Penghitung Debit Air Pada Depot Pengisian Air Minum Isi Ulang Berbasis Arduino", Jurusan Sistem Komputer Fakultas Ilmu Komputer Universitas Narotama Surabaya.

[15] D. Kuriando, A. Noertjahyana, and R. Lim, 2017, "Pendeteksi Volume Air pada Galon Berbasis Internet of Things dengan Menggunakan Arduino dan Android", Fakultas Teknologi Industri Universitas Kristen Petra.

[16] M. Subianto, H. Setiawan, and K. L. Eka S. P., 2018, "Rancang Bangun Prototipe Sistem Kontrol Penggunaan Air Prabayar Berbasis Arduino Uno", Universitas Ma Chung.

[17] Z. Mindriawan, 2018, "Implementasi Internet of Things Pada Sistem Monitoring Suhu dan Kontrol Air Pada Kandang Burung Puyuh Petelur dengan Menggunakan Protokol MQTT", Program Studi Teknik Informatika Fakultas Teknik Universitas Mataram. 